\title{
Transition: What Lies Ahead in the 1990s
}

Relatively few initiatives can sustain themselves in the human services for more than three to five years at a time. The energy level, interest, and enthusiasm associated with different innovations must draw energy from many people, ideally from many disciplines and perspectives, and must meet a legitimate unmet need.

Transition from school to adulthood for young people with disabilities is perhaps one of the more enduring initiatives of the past decade. In the 1980 s we have seen:

- growth of community-based training experiences

- reemphasis by vocational rehabilitation counselors on planning transition with special educators

- more individual written rehabilitation plans which reflect transition objectives for youth with disabilities

- expanded awareness of the high (25-30\%) drop-out rates of youth with disabilities

- more published papers about transition, especially in the area of assessing post-secondary follow-up status

- a majority of states promoting interagency agreements between schools and other local human service agencies

- emergence of detailed individual transition plans for students in local educational agencies

- a change to reflect a specific call for coordinated transition planning for all youth with disabilities

- state system change grants for promoting transition by the U.S. Department of Education

Has progress been made? Absolutely! Have most of the obstacles and challenges of im- plementing meaningful transition been overcome? Absolutely not! There is, unfortunately, an almost overwhelming list of issues, problems, and concerns, requiring concentrated effort. There are consistently high unemployment rates ranging from $40-90 \%$ once youth with disabilities leave school; this is a major target problem. Transition efforts must stay focused on behaviorally measurable and observable outcomes and not become a bureaucratic morass.

What are these problems? What challenges lie ahead for us to make these youth-to-adult transitions successful? Here is my laundry list which I offer for thought, consideration, and review:

1. We need to recognize that parents are not yet fully "on board" regarding transition. Rusch and McNair (1991) recently documented this fact in a parental survey on transition needs. Parents have always been the driving force behind change for children with disabilities. Our efforts here need to be doubled and redoubled.

2. We need to critically analyze and review many of the criticisms made by writers like Edgar (1987), who question the justifiability, integrity, value, and effectiveness of secondary special education curriculum for students with mild disabilities. What revisions or overhauls are required? With what outcomes will we be satisfied? New national models for this group of students will need to be developed and, as Edgar notes, these must not ignore the general problems of the millions of other economically disadvantaged youth in the schools.

3. The soon-to-be reauthorized Rehabilitation Act should reflect tighter connection to tran- 
sition planning for young people with disabilities. Usually this is the first experience of these clients with vocational rehabilitation counselors; these experiences need to be positive.

4. Some states have begun to prioritize adult services, supported employment, etc., for transition-age youth. More states need to do this. If we have failed or partially failed with older people with disabilities, let us not perpetuate this problem. Limited resources should be targeted to transition-age youth.

5. Recent legislation such as the Americans With Disabilities Act and the Technology Assistance Act of 1988 are critically important and should target young people.

Above all, we need to realize that young people with disabilities are first and foremost young people. They will behave and experience many of the same adjustment problems as other teenagers. They will have sexual adjustment problems, self-esteem concerns, and normal home and community adjustment problems.

I suggest that we must look increasingly to the nondisability literature and to nonhandicapped youth for some answers. Also, I suspect that the personal experience of raising a teenager (which I have not yet experienced and am in no rush to get to!) provides a host of insights which can help with life planning in transition programs.

The articles in this memorial issue are excellent. Fittingly, the issue begins with the career ladder concept developed by Shep Siegel, Robert Gaylord-Ross, and their colleagues. This is a comprehensive, longitudinal approach to outcome-based transition. The article by Sowers describes job development and employment outcomes for students with physical and multiple disabilities.

Following this is one of the few articles I am aware of that addresses the challenges of working with transition-age young people with deafblindness. Jane Everson and her associates present a number of the issues involved with this group. Next is an article by Sale and coworkers on the development and quality indicators associated with those schools, postsecondary programs, and communities which practice effective transition. This article is part of an ongoing intensive study of transition at the Virginia Commonwealth University Rehabilitation Research and Training Center.

For those interested in helping young people function independently in competitive work sites and with the help of coworkers, Park and colleagues have put together a stimulating set of case studies describing efficacy and outcomes associated with a good coworker program. With expanded interest in natural supports in job sites, this article bears close scrutiny. We are fortunate to have a contribution from Steve Zivolich, who describes the movement from segregated to integrated employment for young people; this article reflects the rapidly changing gold standard of work outcome values which people with disabilities and their families are going to expect.

Finally, we have an article from Gia BoydKjellan and Jens Bartholin, who describe the Kurator model of transition in Sweden. I believe this important article will help us in the United States realize the international scope of transition. I am indebted to Philip Burke, Ph.D., Chair of the Department of Special Education at the University of Maryland, for making us aware of this work.

This issue marks the end of the first year of the Journal of Vocational Rehabilitation and I wish to thank the increasing number of subscribers and the editorial board for their commitment to developing this journal. From the start our goal has been to pick broad-based topics in vocational rehabilitation which appeal to many people, but especially practitioners. Word of mouth is a powerful way to communicate about a new journal and I thank those of you who have shared copies of the Journal or articles with others and encourage you to help us expand the numbers and diversity of the base of readership. Page six of this issue previews upcoming issues and editors. I am open to your ideas for different issues and look forward to hearing from you.

Paul Wehman 